BULLETIN Bulletin hispanique

HISPANIQUE Université Michel de Montaigne Bordeaux

113-1 | 2011

Actes de 2 colloques

\title{
La difusión de la poesía española impresa en el siglo XVII
}

Trevor J. Dadson

\section{(2) OpenEdition}

Journals

Edición electrónica

URL: http://journals.openedition.org/bulletinhispanique/1307

DOI: 10.4000/bulletinhispanique.1307

ISSN: 1775-3821

Editor

Presses universitaires de Bordeaux

Edición impresa

Fecha de publicación: 1 junio 2011

Paginación: 13-42

ISBN: 978-2-86781-740-3

ISSN: 0007-4640

Referencia electrónica

Trevor J. Dadson, «La difusión de la poesía española impresa en el siglo XVII », Bulletin hispanique [En línea], 113-1 | 2011, Publicado el 01 junio 2014, consultado el 19 abril 2019. URL : http://

journals.openedition.org/bulletinhispanique/1307; DOI : 10.4000/bulletinhispanique.1307

Tous droits réservés 


\title{
La difusión de la poesía española impresa en el siglo XVII
}

\author{
TREVOR J. DADSON \\ Queen Mary, University of London
}

Depuis la publication en 1968 de Construcción crítica y realidad histórica en la poesía española de los siglos XVI y XVII de Antonio Rodríguez-Moñino, liidée que la voie de transmission de la poésie à cette époque passait essentiellement par la copie manuscrite a été communément acceptée. L'inconvénient majeur de la thèse de Rodríguez-Moñino est de faire porter toute l'attention sur la diffusion manuscrite de l'œuvre poétique au détriment du rôle joué par l'imprimerie. L'examen des imprimeries de l'époque et des livres de poésie sortis de leurs presses ainsi que l'analyse des fonds de quelques libraires de Madrid et du contenu de divers inventaires post-mortem, nous permettent de corriger cette distorsion en mettant en relief le rôle important de l'imprimerie dans la diffusion de la poésie espagnole au XVII siècle.

Desde la publicación en 1968 de Construcción crítica y realidad histórica en la poesía española de los siglos XVI y XVII de Antonio Rodríguez-Moñino, ha sido lugar común aceptar su tesis de que la vía de transmisión de la poesía en esta época era principalmente mediante la copia manuscrita. El mayor peligro de la tesis de RodríguezMoñino es que concentramos toda nuestra atención en la difusión manuscrita de la obra poética olvidando por completo el papel que desempeñó la imprenta en esa difusión. Mediante un análisis de las imprentas de la época y los libros de poesía salidos de sus prensas, de los fondos de algunos libreros madrileños, y del contenido de varios inventarios post-mortem, intentamos acabar con esta distorsión subrayando el importante papel que desempeñó la imprenta en la difusión de la poesía española en el siglo XVII.

Ever since the publication in 1968 of Antonio Rodríguez-Moñino's Construcción crítica y realidad histórica en la poesía española de los siglos XVI y XVII, accepting his thesis that poetry in this period was disseminated principally via manuscript copy became commonplace. The greatest danger of Rodriguez-Moñino's thesis is that we concentrate all our attention on the manuscript transmission of poetry and entirely forget the role played by the printing press in this dissemination. Through an analysis of the printing

Bulletin Hispanique, Tome 113, n 1 - juin 2011 - p. 13 à 42. 
houses in that period and the books of poetry that they printed, of the book stock of a number of Madrid booksellers, and of the contents of various post-mortem inventories, we aim at putting an end to this distortion, by underlining the important role played by the printing press in the dissemination of Spanish poetry in the seventeenth century.

Mots-clés : Poésie espagnole - Siècle d'Or - Diffusion - Bibliothèques privées

$S$ I vamos a hablar de la difusión y transmisión de la poesía española impresa durante el siglo XVII, tenemos que tener en cuenta los siguientes factores o grupos: 1) los poetas, es decir, los creadores de lo que se iba a difundir; 2) los editores, o sea, los que costeaban o sufragaban los gastos de la publicación; 3) los impresores; 4) los libreros, que vendían el producto impreso; y 5) los lectores de la obra publicada. Jaime Moll ha resumido el proceso así:

Portador de un texto - ¿en qué condiciones?- [el libro] es un objeto producido mecánicamente, que ha precisado de una inversión económica, que por el hecho de ser producido en ejemplares múltiples exige forzosamente una difusión -su razón de ser- y una serie numerosa de personas interesadas en su adquisición. Aspectos, pues, técnicos, económicos, comerciales, sociológicos, textuales, entre otros, que mucho nos pueden decir y que tanta influencia tienen en el libro, en el autor y en el lector ${ }^{1}$.

Cada uno tiene su parte y papel en el conjunto de lo que podemos llamar la difusión de la poesía impresa en esta época, una época que corresponde plenamente con los mejores años del Siglo de Oro español en lo que a la poesía se refiere. Si tomamos como fecha de partida el ańo de 1560 y los poetas que nacieron a partir de entonces, estamos hablando de poetas de la talla de Luis de Góngora, Lope de Vega, Francisco de Quevedo, Vicente Espinel, los hermanos Argensola, los condes de Salinas y Villamediana, el príncipe de Esquilache, Pedro Calderón, Gabriel Bocángel y Unzueta, Pedro Soto de Rojas, Luis Carrillo y Sotomayor, Juan de Jáuregui, José de Valdivielso, Anastasio Pantaleón de Ribera, Esteban Manuel de Villegas, Francisco López de Zárate, Luis de Ulloa y Pereira, y un muy largo etcétera. Según José Simón Díaz, había en España durante los siglos XVI y XVII unos 24.000 escritores $^{2}$. De éstos, los poetas no eran los menos numerosos.

1. Jaime Moll, «El libro en el siglo de oro», Edad de Oro, n 1, 1982, p. 43.

2. José Simón Díaz, "Los escritores-criados en la época de los Austrias», Revista de la Universidad Complutense, no 2, 1981, p. 169-178, y "Censo de escritores al servicio de los Austrias", en Censo de escritores al servicio de los Austrias y otros estudios bibliográficos, Madrid, 
En un librito que se hizo célebre casi desde el momento de su publicación -Construcción crítica y realidad histórica en la poesía española de los siglos XVI y XVII- Antonio Rodríguez-Moñino hizo unas cuantas afirmaciones sobre la diseminación o no de la poesía impresa en esta época, que desde entonces pocos han querido o intentado refutar. Merece recordar lo que dijo el gran bibliógrafo extremeño:

Para mí, la conclusión parece evidente: el libro, el volumen impreso con la obra lírica de un autor, es excepción en los grandes poetas de los siglos de oro. No importa que Pedro de Padilla, Cristóbal de Mesa, Vicente Espinel o Jáuregui estampen sus rimas, mientras el lector no tenga a su alcance las de los astros de primera magnitud como Garcilaso, Fray Luis de León, San Juan de la Cruz, don Luis de Góngora o don Francisco de Quevedo. Los impresos, pues, no pudieron ser la fuente de un conocimiento amplio, por parte de los contemporáneos, tal como lo son para el lector de hoy ${ }^{3}$.

Esta postura le llevó, naturalmente, a la conclusión de que la vía de transmisión de la poesía en esta época era principalmente mediante la copia manuscrita. Tal es la fuerza y solidez de su argumentación, con muchos datos sobre los poetas que no vieron sus obras impresas en vida, que pocos cambios ha sufrido su tesis en los algo más de cuarenta años que han pasado desde su publicación. Y, sin embargo, como todas las tesis, ésta también es susceptible a la modificación.

Uno de los primeros en ofrecer unas matizaciones a las palabras de Rodríguez-Mońino, en particular en lo referente a la naturaleza de la «realidad histórica» que éste había avanzado, era Pablo Jauralde Pou, quien señaló que en una sociedad mayoritariamente analfabeta la transmisión oral era con mucha diferencia la vía de transmisión más importante y practicada; luego, la vía manuscrita, que para muchos poetas era la ruta preferida al postergar una decisión irrevocable sobre la versión final de un texto. Como dice: «la auténtica realidad histórica es la que conoce y explica los hechos

C.S.I.C., 1983, p. 7-32.

3. Antonio Rodríguez-Moñino, Construcción critica y realidad histórica en la poesía española de los siglos XVI y XVII, Madrid, Castalia, 1968, p. 23-24. Hay que recordar, por supuesto, que el origen de este libro fue la conferencia que Rodríguez-Moñino pronunció en el IX Congreso de la FILLM, celebrado en Nueva York en 1963, conferencia que fue redactada, según el autor, «durante los días 21 y 22 de julio de 1963, sin más libros que los folletos que se citan en el texto y tres o cuatro apuntes que también se mencionan» (Ibid., p. 11). Es decir, hay que tomar con cierta precaución las a veces tajantes afirmaciones, puesto que el autor no disponía en el momento de la redacción de todos los materiales bibliográficos que habrían sido necesarios para un trabajo más riguroso. 
históricos tan peculiares como los que acabamos de enumerar: creación literaria, circulación manuscrita, edición póstuma, etc.» ${ }^{4}$.

Yo intenté, hace unos años, ofrecer también una ligera modificación a la tesis de Rodríguez-Moñino en lo que a la diseminación de la poesía en el siglo XVI se refiere, al mostrar que hubo más poesía española impresa en el XVI de lo que a primera vista parece, especialmente vía las colecciones colectivas como los cancioneros y romanceros que empezaron a florecer entonces, y también vía las novelas mayormente pastoriles que a menudo contenían poemas 5 .

Más recientemente, Antonio Carreira, en una muy sugerente contribución a un libro colectivo sobre el Barroco, ha vuelto a subrayar el papel central del manuscrito en la transmisión de la poesía del Barroco español ${ }^{6}$. Sin embargo, al contrario de Rodríguez-Mońino, reconoce que la copia manuscrita muchas veces convivía con y al lado de la copia impresa. El cartapacio manuscrito de sus versos tenía, para el poeta, la gran ventaja de que no significaba un punto final de composición, como lo hacía el libro impreso; siempre podía ir añadiendo más poemas a los que ya tenía escritos ${ }^{7}$. Era, en fin, un proyecto continuo, siempre en marcha ${ }^{8}$. Carreira nos da el ejemplo de Góngora, cuya obra se imprimió «con rara celeridad, sólo meses después de su muerte»; aún así «se conservan más de treinta manuscritos integri de su obra, es decir, de los que pretenden abarcarla en su totalidad»?. También nos recuerda Carreira que el manuscrito, para el siglo XVII, había logrado el estatus de objeto preciado y valorado, representaba un texto único, no como el libro impreso con sus tiradas de 1.500 ejemplares, todos más o menos iguales. De ahí que vayamos encontrando manuscritos preparados con gran esmero y cuidado, muchas veces destinados a un comprador o poseedor rico, algo así como el coleccionista de objetos de arte de hoy en día. Ejemplos de ellos son el famoso manuscrito Chacón con las obras de Góngora, copiadas en

4. Pablo Jauralde Pou, «El público y la realidad histórica de la literatura española de los siglos XVI y XVII", Edad de Oro, n 1, 1982, p. 57.

5. Trevor J. Dadson, "The Dissemination of Poetry in Sixteenth-Century Spain», Journal of the Institute of Romance Studies, n ${ }^{\circ} 8,2000$, p. 47-56.

6. Antonio Carreira, «El manuscrito como transmisor de humanidades en la Espańa del Barroco», en P. Aullón de Haro (ed.), Barroco, Madrid, Verbum, 2004, p. 597-618.

7. Ver Trevor J. Dadson, «Editing the Poetry of don Diego de Silva y Mendoza, Count of Salinas and Marquis of Alenquer", Bulletin of Hispanic Studies, n 85, 2008, p. 285-331, para un análisis de la creación y formación de la obra poética del conde de Salinas mediante el cartapacio en continuo estado de revisión y aumento.

8. Moll habla de una larga etapa de «fluctuación textual» que la obra impresa cerró con su «fijación definitiva de los textos» (art. cit., p. 43).

9. Carreira, art. cit., p. 610. 
preciosa vitela en tres volúmenes, y el manuscrito de diversas poesías que Manuel Faria e Sousa preparó para el Conde de Haro (BNE ms. 3992) ${ }^{10}$.

El mayor peligro de la tesis de Rodríguez-Mońino, y en el que, a decir verdad, no cae Carreira, es que puede llevar al conformismo entre los críticos, que creen que no hay que cuestionar algo tan sólidamente fundamentado. Y, así, concentramos toda nuestra atención en la difusión manuscrita de la obra poética olvidando por completo el papel que desempeñó la imprenta en esa difusión, bastante mayor en el siglo XVII que en el XVI. Evidentemente, la difusión vía la copia manuscrita era una realidad, y no voy a ser yo quien lo cuestione, habiendo pasado tantos años intentando resolver los problemas editoriales que presentan los múltiples manuscritos que contienen poemas del conde de Salinas, poeta que jamás vio impresa su obra ${ }^{11}$. Sin embargo, ignorar el creciente uso de la imprenta en el siglo XVII para propagar la obra poética llevaría a otra distorsión de la realidad.

De lo que no cabe duda, en mi opinión, es de que entre finales del siglo XVI y principios del XVII las condiciones literarias sufrieron un cambio bastante radical. Durante buena parte del XVI los monarcas españoles mantuvieron a los nobles apartados y bien lejos de la Corte y del poder asociado con ella, prefiriendo tenerlos repartidos por el país y ocupados en sus diversos estados. Aunque la decisión de Felipe II de establecer la capitalidad en Madrid en 1561 contribuyó a hacer de ella la capital literaria del país, los efectos tardaron en verse y realmente no se manifestaron hasta el reinado de su hijo, Felipe III. Felipe II desconfiaba de la nobleza y siempre tuvo cuidado de que no consiguiera acumular demasiado poder, pero con su hijo el cambio fue repentino y decisivo. Nada más subir al trono, Felipe III entregó el poder efectivo a su favorito o valido el duque de Lerma, que, para tener al monarca divertido y ocioso, animó a los nobles a volver a la Corte. Como Corte y Villa, Madrid se convirtió inmediatamente en el centro de la vida literaria del país. Y con la llegada de los nobles ansiosos de participar en este mundo de diversión y placer, llegaron también muchos escritores que encontraban en las casas nobles y la casa real empleo como secretario (Lupercio Leonardo de Argensola, Lope de Vega, Antonio Hurtado de Mendoza, Francisco de Quevedo, Pedro Calderón), bibliotecario (Francisco de Rioja, Gabriel Bocángel), capellán (Bartolomé Leonardo de Argensola,

10. Para más sobre la relación entre el manuscrito y el libro impreso en el siglo XVII, ver Trevor J. Dadson, «La imprenta manual y los textos poéticos», Edad de Oro, n 28, 2009, p. 73-104.

11. Ver Trevor J. Dadson, "Hacia una edición crítica de la poesía del Conde de Salinas», en J. Cañedo \& I. Arellano (eds.), Edición y Anotación de Textos del Siglo de Oro, Pamplona, Anejos de RILCE, 4, 1987, p. 51-68, y «Editing the Poetry of don Diego de Silva y Mendoza, Count of Salinas and Marquis of Alenquer», art. cit. 
Luis de Góngora, José de Valdivielso, Mira de Amescua), caballerizo (García de Salcedo Coronel) ${ }^{12}$. Con el mecenazgo de la nobleza y la monarquía y un salario (aunque a menudo ni grande ni regular), el escritor podía dedicar más tiempo a ver impresa su obra, al contrario de su homólogo del siglo XVI. El escribir empezó a convertirse por tanto en una ocupación profesional y no, como en el siglo anterior, una diversión o pasatiempo. Como ha señalado muy atinadamente Ignacio García Aguilar:

la presencia del noble en el objeto impreso dotaba al libro de un cierto halo de importancia y predisponía una cierta actitud de respeto ante la lectura del volumen [...] La poesía impresa, con mayor razón si cabe, busca en los poderosos la protección tipificada y preceptiva, pero sobre todo una posibilidad de promoción social e institucionalización literaria ${ }^{13}$.

Garcilaso era principalmente un soldado, un diplomático y un cortesano; para él, escribir era algo que hacía hurtando el tiempo a sus otras ocupaciones, como nos dijo en unos versos memorables de su Égloga III: «hurté del tiempo aquesta breve suma, / tomando ora la espada, ora la pluma» ${ }^{14}$.

Fray Luis de León era, antes que nada, un catedrático universitario y monje agustino, para quien la poesía era más bien un pasatiempo. Por eso, pudo escribir, imitando a Ovidio: «Entre las ocupaciones de mis estudios en mi mocedad, y casi en mi nińez, se me cayeron como de entre las manos estas obrecillas» ${ }^{15}$. Francisco de Aldana, Gutierre de Cetina, Hernando de Acuña, Francisco de Figueroa, y otros muchos, eran soldados que luchaban por su país en el extranjero. Que, en estas circunstancias, escribieran poesía es de por sí casi un milagro; que sobreviviera, aún más, especialmente cuando, como en el caso de Aldana, murieron fuera de España. No sorprende, por tanto, que no supervisaran ni dirigieran la publicación de sus versos. En algunos casos esto fue emprendido por amigos o parientes, a veces con resultados más bien desastrosos, como pasó con la poesía de Aldana (muerto en la batalla de Alcazarquivir) que fue publicada en Milán en 1589 por su hermano Cosme. En resumen, las condiciones materiales tanto para el poeta como para la poesía cambiaron sustancialmente entre los siglos XVI y XVII,

12. Para una lista bastante completa, ver los dos trabajos antes citados de Simón Díaz (nota 2).

13. Ignacio García Aguilar, Poesía y edición en el Siglo de Oro, Madrid, Calambur, 2009, p. 160 y 163.

14. Garcilaso de la Vega, Obras completas, ed. Elias L. Rivers, Madrid, Castalia, 1968, p. 141.

15. Fray Luis de León, Poesías, ed. P. Ángel Custodio Vega, Barcelona, Planeta, 1970, p. 5. 
y eso es evidente, como iremos viendo, en el número de libros de poesía que se imprimieron en el XVII, algunos más de una vez.

Para Carreira, un fuerte argumento en contra de esta tesis es el coste real de la publicación:

Pero imprimir un libro de poemas en los siglos XVI y XVII era muy costoso y requería un mecenazgo no siempre fácil de encontrar. Por ello gran cantidad de poetas murieron sin entregar su obra a la imprenta, incluso sin prepararla para la estampa o la reproducción manual, lo que origina problemas graves de ordenación y autoría ${ }^{16}$.

El coste de la publicación es, evidentemente, un factor muy importante a tener en cuenta, y puede que haya desanimado a algún que otro poeta a emprender el camino de la publicación de sus versos, pero el gran número de libros de poesía impresos entre 1600 y 1650 en Espańa prueba que no fue un factor tan decisivo a la hora de elegir esta ruta. Como he señalado antes, muchos escritores encontraron empleo en casas nobles o en la Casa Real, y las más de las veces consiguieron el empleo después de haber dedicado algún libro suyo al noble o príncipe en cuestión. Es decir, había una relación muy directa entre el mecenas y el beneficiado, y los versos de éste eran primordiales en ella. Los esfuerzos, infructuosos, de Cervantes por conseguir el mecenazgo del duque de Béjar y luego del conde de Lemos son bien conocidos, lo mismo los de Góngora por conseguir el mecenazgo de alguien del círculo del duque de Lerma, también sin éxito. Es probable que estos dos ejemplos negativos hayan influido demasiado en nuestra visión del mecenazgo de esta época. Pero por cada Cervantes y Góngora que fracasaron en sus intentos de encontrar un mecenas había otros que sí lo consiguieron, como Lope de Vega con el duque de Sessa, Quevedo con el duque de Osuna, los hermanos Argensola con el conde de Lemos, Bocángel y Salcedo Coronel con el Cardenal-Infante ${ }^{17}$.

Algo que tenía el siglo XVII que no tenía el XVI era, por supuesto, Lope de Vega. Lope fue un fenómeno de la creación literaria y de la publicación ${ }^{18}$.

16. Carreira, art. cit., p. 610.

17. Moll establece una distinción importante entre el mecenas, objeto de dedicación del libro, y el librero-editor que es el que las más de las veces lo financia: «En algunos casos, un protector del escritor puede financiar la edición. Debo señalar que, a mi parecer, se ha abusado al considerar como mecenas las personas a quienes se dedica un libro [...] Son pocas las ocasiones en que los llamados mecenas financian una edición» (art. cit., p. 46). Ahora bien, lo que sí hacen algunos de ellos es ofrecer una estabilidad económica al escritor, lo que le permite escribir. En este caso, la relación mecenas-escritor ha funcionado bien.

18. Sobre el fenómeno editorial de Lope de Vega, es imprescindible el trabajo de Ignacio García Aguilar, Imprenta y Literatura en el Siglo de Oro. La poesía de Lope de Vega, Madrid, 
Consistiendo en más de 1.500 comedias escritas (según el mismo autor), numerosos libros de poesía, novelas, la obra de Lope empezó a publicarse en 1599 con la Arcadia y siguió sin parar hasta su muerte en 1635. Fue de los primeros escritores, tal vez el primero, en España que logró vivir de su obra, y su ejemplo tenía que haber calado entre escritores más jóvenes que veían su éxito y querían imitarlo. El gran éxito de Lope también tiene que haber influido en la mente de los impresores y libreros que veían cómo la poesía podía venderse, que no era cosa de unos pocos sino que era capaz de llegar a un público más extendido y variado. Si tomamos como ejemplo el primer libro de verso de Lope que acabo de mencionar, la Arcadia, impreso en Madrid en 1599 por Pedro de Madrigal, y el período que va de 1600 a 1620, fue publicado de nuevo en 1602 en Madrid, Valencia y Barcelona; en 1603 en Madrid; en 1605 en Amberes y Madrid; en 1611 en Madrid, en 1612 en Lérida, en 1615 en Lérida y Barcelona, en 1617 en Amberes y Lérida, y de nuevo en Madrid en 1620. Es decir, unas trece ediciones en sólo veinte ańos, lo que representa unos 19.500 ejemplares. Al mismo tiempo, habían aparecido en el mercado otras obras de Lope que competían con la Arcadia en popularidad, de ahí que a partir de 1605 el número de ediciones disminuyera y éstas se esparcieran más en el tiempo.

Si de las obras de Lope pasamos al panorama más amplio de la impresión de obras poéticas durante la primera mitad del siglo XVII, vemos, por el siguiente gráfico, que ésta fue alta y constante:

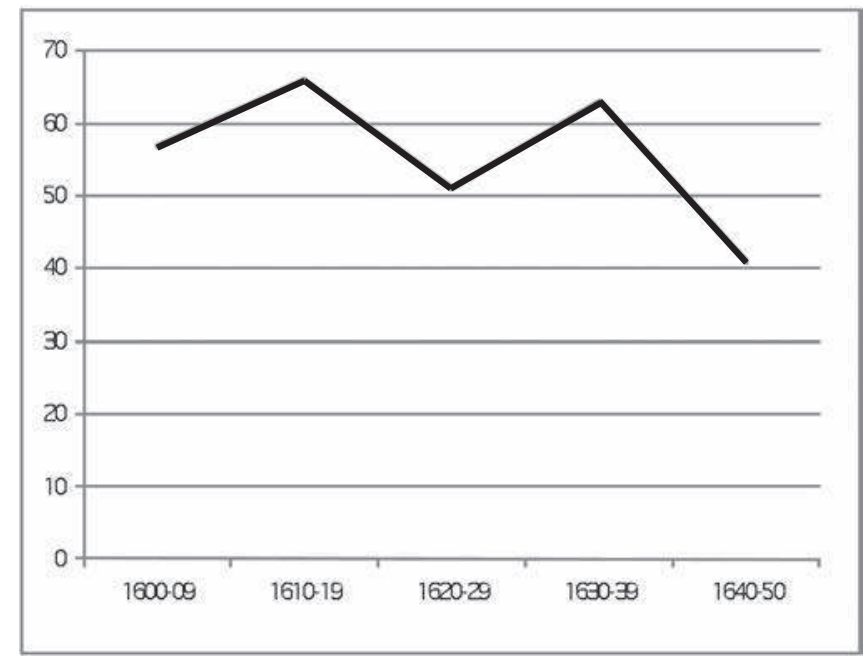

Libros de poesía publicados en España, 1600-50

Ediciones del Orto/Universidad de Minnesota, 2006. 
En total, son unas 278 ediciones de libros de poesía, que, a un promedio de 1.000 a 1.500 ejemplares la tirada, hacen un total de entre $278.000 \mathrm{y}$ 417.000 ejemplares individuales impresos entre 1600 y $1650^{19}$. Esta cifra indudablemente peca de corta, ya que no incluye los pliegos sueltos poéticos, que se imprimieron por miles y que, para muchos, eran el vehículo principal mediante el cual llegaban a conocer la poesía barroca, ni todos los cancioneros y romanceros que recogió Rodríguez-Moñino ${ }^{20}$, ni todas las ediciones salidas de las imprentas españolas, ya que aún nos faltan tipobibliografías para ciudades tan importantes como Barcelona, Valencia, Salamanca y Burgos para la primera mitad del siglo XVII. Aún así, son muchos libros de poesía, lo que pone en entredicho, creo yo, la idea tan firmemente asumida de que el libro impreso no fue el transmisor de la poesía en el Barroco español ${ }^{21}$.

19. El tamaño de la tirada normal en esta época es un punto espinoso entre los expertos en la materia. Según Christian Péligry («Un libraire madrilène du siècle d’or. Francisco López le Jeune (1545-1608)», Mélanges de la Casa de Velázquez, n 12, 1976, p. 238), el número de ejemplares de las ediciones costeadas por Francisco López el Joven oscilaba entre 1.000 y 1.750, lo normal siendo 1.500. Para las prensas de Zaragoza, Esperanza Velasco de la Peña ha dicho que «Nuestras prensas podían producir 1.530 pliegos en una jornada de trabajo y al impresor se le pagaba, generalmente, por pliego impreso" (Impresores y libreros en Zaragoza, 1600-1650, Zaragoza, Institución «Fernando el Católico», 1998, p. 52). Jean-Michel Laspéras también se decanta por esta cantidad: «Aunque Francisco Rodríguez Marín afirma en Estudios Cervantinos (Madrid, Atlas, 1947, p. 106) que "las obras de entretenimiento no se estampaban arriba de setecientos cincuenta", cuando se trataba de la primera edición, tenemos con este ejemplo [las Obras de Diego Hurtado de Mendoza, Madrid, 1610] y con el de Arauco domado, del cual quedaban 1.088 cuerpos en la tienda de Francisco López, en 1608, una prueba más para afirmar que tales tiradas se situaban entre 1.200 y 1.500 ejemplares» («El fondo de librería de Francisco de Robles, editor de Cervantes», Cuadernos Bibliográficos, $n^{\circ} 37,1979$, p. 137 n. 23). En el famoso libro de Alonso Víctor de Paredes, leemos que «En las jornadas de mil y quinientos, dos mil, ò mil y setecientos y cinquenta, que se tiran dos formas cada dia, ha de tener el Componedor correcto su blanco à las doze, y el Tirador acabada su retiracion à la misma hora. En las de mil, ò mil y ciento...» (Institución y origen del Arte de la Imprenta y reglas generales para los componedores, edición y prólogo de Jaime Moll, Madrid, El Crotalón, 1984; segunda edición: Madrid, Calambur, 2002, fol. 43v). Es decir, Paredes habla de tiradas de entre mil y dos mil, siendo la primera mencionada la tirada de 1.500 .

20. Antonio Rodríguez-Moñino, Manual bibliográfico de cancioneros y romanceros impresos durante el siglo XVII, 2 vols, Madrid, Castalia, 1977-1978. Por ejemplo, la Historia del muy noble y valeroso caballero el Cid de Juan de Escobar conoció 15 ediciones entre 1600 y 1650; la Primavera y flor de los mejores romances recopilada por Pedro Arias Pérez 17 ediciones en el mismo período; el Romancero espiritual de José de Valdivielso, 11 ediciones, y así muchos más cancioneros y romanceros.

21. El libro reciente de García Aguilar (Poesía y edición en el Siglo de Oro) viene a apoyar y explicitar aún más esta línea de investigación con numerosos ejemplos que demuestran la importancia del libro impreso de poesía en el Barroco. 
Estos miles de ejemplares salían de las imprentas de todas las principales ciudades del país: Madrid, Barcelona, Valencia, Zaragoza, Sevilla, Valladolid; algunos de las secundarias: Lérida, Córdoba, Antequera, y otros de imprentas extranjeras, como las de Amberes, Bruselas, Lisboa, Palermo y Milán. Sin embargo, el peso de las imprentas madrileñas en esta producción excede a todas las demás juntas. Las imprentas de Pedro de Madrigal, Juan de la Cuesta, Luis Sánchez, la Imprenta Real, Juan Flamenco, Alonso Martín (luego su viuda), Juan González, Diego Flamenco, Imprenta del Reino, María de Quiñones, Diego Díaz de la Carrera, y otras muchas, fueron los más importantes participantes en esta empresa, y algunas llegaron a dominar el mercado como las imprentas de Pedro de Madrigal, Juan de la Cuesta, la viuda de Alonso Martín, Luis Sánchez, la Imprenta Real y Diego Díaz de la Carrera.

Trabajando en cercana asociación con las imprentas estaban los libreros o editores que costeaban las ediciones. Por lo general, ellos ponían el dinero necesario para la edición, pagando antes un tanto al autor por los derechos o privilegio de publicación. A veces el autor recibía gratis, además de una cantidad de dinero, unos cuantos ejemplares del libro para repartir entre amigos y deudos (muy parecido, la verdad, a lo que pasa hoy en día con muchas editoriales). El librero editor asumía, por tanto, los riesgos de la edición, pero, si era un éxito, salía con unos pingües beneficios. Christian Péligry ha resumido muy bien el papel fundamental del librero en el proceso de la impresión:

Le libraire qui se chargeait de l'édition d'un ouvrage, engageait souvent des sommes importantes dans cette opération, car il prenait à son compte tous les frais survenus avant, pendant, et après l'impression. C'était lui qui fournissait généralement le papier à l'imprimeur; or, cette matière coûtait cher, et pesait très lourd dans le prix de revient d'une édition [...] Outre le papier qu'il devait lui fournir, le libraire payait à l'imprimeur le travail des ouvriers qui s'affairaient autour de la presse ${ }^{22}$.

$\mathrm{Al}$ entregar el autor su original al librero o editor, recibiendo a cambio un pago, dejaba de tener derechos sobre el producto final; esto ha llevado a muchos a afirmar que el autor dejaba a partir de este momento de tomar más parte en el asunto, dejando todo en manos del editor e impresor. En especial, esto significaría que no tomara parte en la preparación ni corrección de su obra, de ahí que, para algunos, salgan tantas erratas en estas ediciones.

22. Péligry, art. cit., p. 239. 
Como he demostrado en varios trabajos, esto no es cierto en todos los casos y tenemos bastantes ejemplos de la presencia del autor en la imprenta que corregía los pliegos mientras éstos salían de la prensa ${ }^{23}$. Esto se nota especialmente en los libros de poesía, donde parece que los poetas tenían bastante más interés que otros autores en que sus obras saliesen correctas y libres de erratas.

No obstante la presencia del autor en la imprenta, el papel desempeñado por el librero o editor es fundamental en todo este proceso, y algunos libreros llegaron a dominar el mercado hasta tal punto que no es exagerado decir que determinaban más que nadie qué libros se publicaban y cuáles no. Principales entre ellos eran Francisco López el Joven, Francisco de Robles, Miguel Martínez, y Alonso Pérez.

Haciendo como de puente entre finales del siglo XVI y principios del XVII, Francisco López el Joven (para distinguirlo de su padre del mismo nombre) costeó, entre 1597 y su muerte acaecida el 2 de septiembre de 1608, al menos una docena de obras, entre ellas: las poesías de Garcilaso de la Vega (Francisco Sánchez, 1600), la Vida de la madre Teresa de Jesús (Francisco de Ribera, 1602), un Romancero general (1604), un poema épico de Pedro de Ońa titulado Arauco domado (1605), y dos libros de Juan de los Ángeles. Antes de estas fechas había costeado la publicación de diversas obras en Burgos y Alcalá. Péligry ha descrito así su labor de editor:

Francisco López a su, en définitive, prendre en mains ses responsabilités d'éditeur. Il ne s'est spécialisé dans aucun domaine et préféra, au contraire, étendre le champ de ses publications de la médecine à la littérature ascétique, en passant par le droit, la poésie, les mathématiques et l'art militaire. Le choix des ouvrages qu'il a confiés à la presse révèle, chez lui, un esprit curieux, ouvert, à l'affût des nouveautés, et nous laisse entrevoir, en même temps, le sens des réalités d'un homme soucieux de faire prospérer son commerce ${ }^{24}$.

23. Ver Trevor J. Dadson, «Some Problems Connected with the Printing and Dating of Gabriel Bocángel's La lira de las Musas", Modern Language Review, n 76, 1982, p. 848-859; «El autor, la imprenta, y la corrección de pruebas en el siglo XVII», El Crotalón. Anuario de Filología Española, n ${ }^{\circ} 1,1984$, p. 1053-1068; «La corrección de pruebas (y un libro de poesía)», en F. Rico (ed.), Imprenta y crítica textual en el Siglo de Oro, Valladolid, Fundación Santander Central Hispano. Centro para la Edición de los Clásicos Españoles, 2000, p. $97-$ 128; "Entre componedores y correctores», en José Manuel Lucía Megías (ed.), Imprenta, libros y lectura en la España del Quijote, Madrid, Ollero y Ramos, 2006, p. 225-242.

24. Péligry, art. cit., p. 243. 
El inventario del fondo de su librería, hecho a su muerte en 1608, revela que consistía en estos momentos en unos 15.000 volúmenes, lo que representa una gran cantidad suya de dinero invertido. Muchos de estos tomos eran ejemplares de libros que él mismo había costeado, como los 1.088 ejemplares del poema Arauco domado (con un valor de 2.172 reales), los 128 del Romancero general (768 reales), o los 180 de las obras poéticas de Garcilaso (a 1 real cada uno). Como dice Péligry, Francisco López sólo recuperaba lentamente las importantes sumas invertidas en sus operaciones comerciales, teniendo que esperar, en el mejor de los casos, una docena de años antes de cubrir enteramente los costes de una edición que él mismo había financiado. No era, desde luego, el del librero editor un negocio a corto plazo.

Después de Francisco López, Francisco de Robles fue, probablemente, el librero más importante de Madrid durante los primeros años del siglo XVII en lo que a la publicación de libros se refiere, costeando decenas de ellos, pero tuvo poco interés en la poesía. Trabajando conjuntamente con el impresor Juan de la Cuesta, costeó las siguientes ediciones: en 1604, el Romancero general. Ahora nuevamente añadido y enmendado, y en 1610, las Obras de Diego Hurtado de Mendoza. Al igual que pasó con Francisco López, cuando Francisco de Robles murió en 1623 se encontraban en su librería varios ejemplares de libros que él mismo había costeado y aún no vendido, entre ellos 914 Obras de Diego Hurtado de Mendoza (Madrid, 1610), señal, según Laspéras, de su rotundo fracaso como negocio editorial ${ }^{25}$. Otros libros de poesía que tenía al momento de su muerte eran:

7 Rimas sacras de Lope de Vega (Madrid, 1614)

3 Obras de Luis Carrillo y Sotomayor (Madrid, 1611)

93 Arauco domado de Pedro de Ońa (Madrid, 1605)

13 El peregrino en su patria de Lope de Vega (Sevilla, 1604)

18 Conceptos espirituales de Alonso de Ledesma (Madrid, 1612)

Al llegar a la segunda década del siglo, Robles empezó a dar paso a otro librero, Alonso Pérez, que sin lugar a dudas fue el librero que más influencia ejerció sobre la producción y publicación de libros de poesía en la primera mitad del siglo. El número de ediciones que costeó es asombroso e impresionante: 44, durante un período de cuarenta años. El primer libro de poesía que costeó fue Esteban de Villalobos (ed.), Primera parte del tesoro de divina poesía (Madrid: Luis Sánchez, 1604) y el último en 1644: Luis Ramírez de Arellano (ed.), Avisos para la muerte (Madrid: Imprenta del

25. Laspéras, art. cit., p. 137. 
Reino). La nómina de poetas que gracias a Alonso Pérez vieron impresas sus obras es toda una lista de los mejores poetas de la época: hasta 1621 sólo costea ediciones de Lope de Vega, con alguna de Alonso de Ledesma, pero después ( $\mathrm{y}$ tal vez debido al dinero ganado con las ediciones siempre populares de Lope) empieza a expandir sus horizontes y encontramos a los siguientes autores: Miguel Botello, Francisco de Francia y Acosta, Juan Pérez de Montalbán (su hijo), Gabriel de Corral, Luis de Góngora, Gabriel Bocángel, Salvador Jacinto Polo de Medina, Pedro de Castro y Anaya, Luis Ramírez de Arellano, y Pedro Grande de Tena.

Al mismo tiempo, y como librero, actuó, seguramente, como el mayor vehículo de transmisión de la obra poética impresa en esta época. Entre los fondos de su gran librería, inventariados en 1648, encontramos los siguientes títulos:

405 Lágrimas de Montalbán (Madrid, 1639)

118 Obras de Góngora (Madrid, 1627, 1633, 1634)

57 La Vega del Parnaso de Lope de Vega (Madrid, 1637)

744 Orfeo de Juan Pérez de Montalbán (Madrid, 1624)

46 Rimas de Burguillos de Lope de Vega (Madrid, 1634)

503 Cintia de Aranjuez de Gabriel del Corral (Madrid, 1629)

89 Romancero del Cid recopilado por Juan de Escobar (Alcalá, 1612)

64 Obras de Quevedo (Madrid, 1644 o 1645)

340 Rimas de Argensola (Zaragoza, 1634)

21 Arcadia de Lope de Vega (Madrid, varias impresiones)

896 San Isidro de Lope de Vega (Madrid, 1638)

21 Obras de Villamediana (Madrid, 1635, 1643)

220 Corona trágica de Lope de Vega (Madrid, 1627)

26 Flor de varios romances nuevos (Barcelona, 1646)

19 Laurel de Apolo de Lope de Vega (Madrid, 1630)

19 Lira de las Musas de Gabriel Bocángel (Madrid, 1637)

123 Justa poética de Lope de Vega (Madrid, 1620)

313 Auroras de Diana de Pedro de Castro (Madrid, 1637)

3 Rimas de Salas Barbadillo (Madrid, 1618)

6 Obras de Diego Hurtado de Mendoza (Madrid, 1610)

6 Obras de Fray Luis de León (Madrid, 1631)

8 Fama pósthuma de Lope de Vega (Madrid, 1636)

7 Versos de Fernando de Herrera (Sevilla, 1619)

12 Rimas de Colodrero de Villalobos (Córdoba, 1629)

1600 Avisos para la muerte, Luis Ramírez de Arellano (Madrid, 1643)

1 Poesia de Saa de Miranda (Lisboa, 1632)

2 Las 300 de Juan de Mena (Sevilla, 1499)

2 Flores divinas de Faria y Sousa (Madrid, 1624) 
1 Obras de Aldana (Madrid, 1593)

1 Obras de Castillejo (Madrid, 1573, 1600)

1 Arauco domado de Pedro de Ońa (Madrid, 1605)

1 Conceptos espirituales de Alonso de Ledesma (Madrid, 1603)

1 Viaje del Parnaso de Cervantes (Madrid, 1614)

1 Camóes comentado (Madrid, 1639) ${ }^{26}$

Para el amante de la poesía, la librería madrileña de Alonso Pérez tenía que haber sido el paraíso en la tierra. Aunque la suya era un caso aparte, excepcional, otras librerías madrileñas también distribuían las obras poéticas impresas, como la del joven librero Cristóbal López, muerto en 1606:

1500 Marqueses de Mantua

1400 Coplas del Hermano Francisco de Alcalá (Madrid, 1606)

139 Arcadia de Lope de Vega (Madrid, 1605)

10 Poetas ilustres de Pedro de Espinosa (Valladolid, 1605)

82 Hermosura de Angélica de Lope de Vega (Madrid, 1602)

7 Segunda parte del Romancero general (Valladolid, 1605)

23 Isidro de Lope de Vega (Madrid, 1602)

6 Romancero general (Madrid, 1600, 1604)

4 Peregrino en su patria de Lope de Vega (Sevilla, 1604)

7 Arauco domado de Pedro de Oña (Madrid, 1605)

5 Romancero general primera y segunda partes

2 Cancionero de Lope de Maldonado (Madrid, 1586)

8 Obras de Gregorio Silvestre (Granada, 1599)

3 Obras de Castillejo (Madrid, 1573, 1600)

1 Tesoro de divina poesía de Villalobos (Madrid, 1604)

5 Conceptos espirituales de Ledesma (Madrid, 1604)

1 Dragontea o tercera parte de las Rimas de Lope de Vega (Madrid, 1598)

1 Lusíadas de Camoes (Madrid, 1591, en la traducción de Enrique Garcés)

4 Romancero chicos $=$ Flor de varios romances nuevos en $12^{\circ}$ (Madrid, 1597)

6 Araucana de Ercilla, las 3 partes (Madrid, 1597)

6 Garcilaso de la Vega (Madrid, 1600)

1000 pliegos de Coplas ${ }^{27}$

26. Información de Anne Cayuela, Alonso Pérez de Montalbán. Un librero en el Madrid de los Austrias, Madrid, Calambur, 2005.

27. Información de Trevor J. Dadson, «La librería de Cristóbal López (1606): Estudio y análisis de una librería madrileña de principios del siglo XVII», en Pedro Cátedra \& María Luisa Vidriero (eds.), El libro antiguo español IV. Coleccionismo y Bibliotecas (Siglos XVIXVIII), Salamanca, Universidad de Salamanca, Sociedad Española de Historia del Libro, 1998, p. 167-234. 
Teniendo en cuenta que la librería de Cristóbal López llevaba pocos años funcionando y que el librero murió bastante joven, esta lista de libros de poesía y la variedad de ella demuestran que, con el tiempo y no mediando la muerte, Cristóbal López habría llegado a ser otro Alonso Pérez. Es evidente que costeó la publicación de los romances El marqués de Mantua, de las Coplas del Hermano Francisco de Alcalá, y los 1000 pliegos de Coplas sin nombrar, al tener en su librería casi la totalidad de la tirada de cada una de ellas.

Otra librería madrileña donde encontramos algunos libros de poesía a la venta era la de Sebastián de Robles (muerto en 1612):

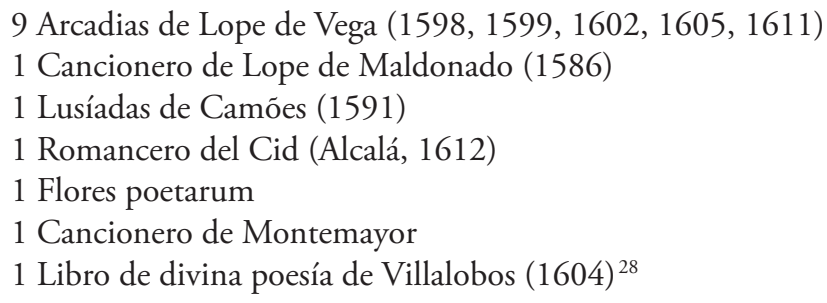

Desafortunadamente, se han encontrado y estudiado pocos fondos de librería para esta época; los conocidos son: Cristóbal López (1607), Francisco López (1608), Sebastián de Robles (1612), Damián Ruiz (1619), Francisco de Robles (1623), Miguel Martínez (1629), Alonso Pérez (1648), y Manuel López del Castillo (1662) ${ }^{29}$. Todas éstas son librerías madrileñas. Fuera de la capital, la situación para el mercado del libro no era demasiado buena, como demostró hace años Péligry ${ }^{30}$. En muchas ciudades se nota un declive en el número de ediciones impresas, que empieza en Medina del Campo a partir de 1608, en Sevilla a partir de 1620, y en Toledo a partir de 1626, lo mismo que para Alcalá y Valladolid. Sólo las imprentas de Madrid van en contra de esta tendencia, con su decena de imprentas y sus 38 prensas funcionando en 1640 .

28. Ver Christian Péligry, «El inventario de Sebastián de Robles, librero madrileño del siglo XVII», Cuadernos Bibliográficos, n 32 , 1975, p. 181-188.

29. Además de los trabajos ya citados, ver Trevor J. Dadson, «El mercado del libro en Madrid durante el primer tercio del siglo XVII. Algunos apuntes y un inventario», Litterae [en prensa], para Damián Ruiz; Dadson, «La librería de Miguel Martínez (1629), librero y editor del primer tercio del siglo XVII», Bulletin Hispanique, n 99, 1997, p. 41-71; y el Marqués del Saltillo, «Bibliotecas, libreros e impresores madrileños del siglo XVII», Revista de Archivos, Bibliotecas y Museos, ${ }^{\circ}$ 54, 1948, p. 255-285, para Manuel López del Castillo.

30. Christian Péligry, «Les difficultés de l'édition castillane au XVII siècle», Mélanges de la Casa de Velázquez, $\mathrm{n}^{\circ} 13,1977$, p. 257-284. 
Hemos visto, entonces, que al lector o amante de la poesía no le faltaban ediciones impresas de sus poetas favoritos. Con unos 417.000 ejemplares, como mínimo, de poesía impresos entre 1600 y 1650, había suficientes para todos. Y si se imprimieron tantos ejemplares está claro que había para ellos un público lector deseoso de comprar estos textos y leer sus versos ${ }^{31}$. Ahora bien, este panorama esconde una distorsión bastante grande y ésta es el efecto Lope. Hubo al menos 66 ediciones de sus obras en este período, es decir, un $23,7 \%$ del total de ediciones conocidas. Otro que disfrutó de una popularidad fuera de lo normal era Alonso de Ledesma, en especial su obra Conceptos espirituales: hemos contabilizado unas 29 ediciones de Ledesma, o un $10,4 \%$. Juntos copan el $34 \%$ del total de libros de poesía impresos entre 1600 y 1650 . Pero lo interesante es observar cómo su popularidad, muy fuerte en las dos primeras décadas del siglo XVII, sufre un declive muy notable a partir de la década de 1620 , que es precisamente cuando entra en escena la nueva generación de poetas influidos, en su mayoría, por la poesía de don Luis de Góngora:

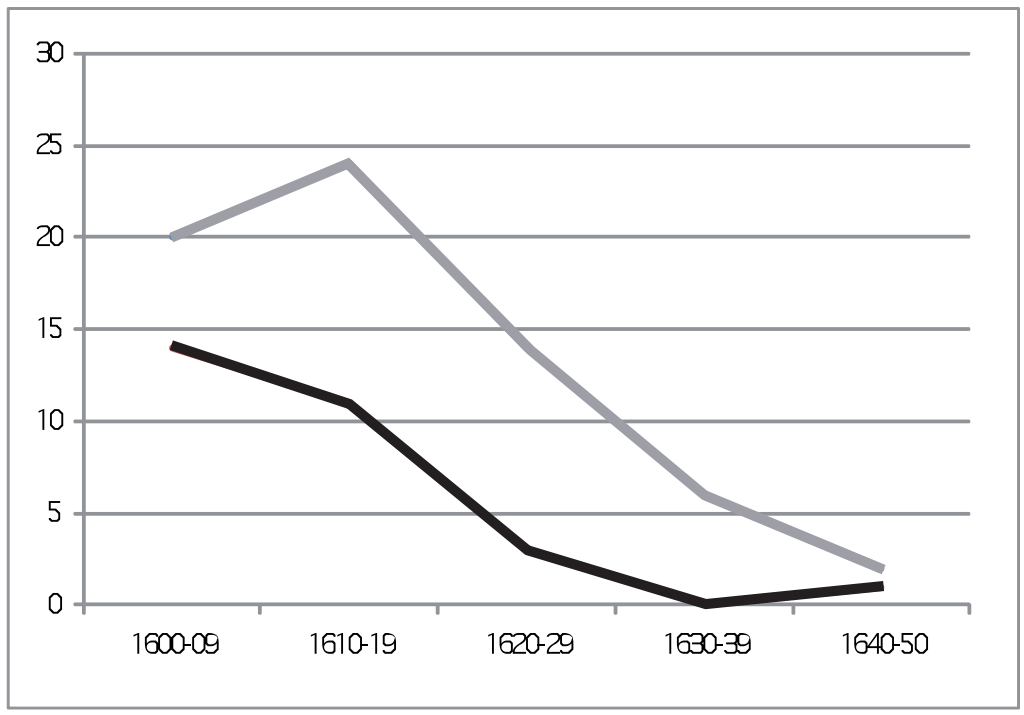

Libros de poesía impresos de Lope de Vega (línea gris) y Alonso de Ledesma (línea negra) entre 1600 y 1650

31. Cf. lo que dice al respecto García Aguilar: «Observamos, pues, que la poesía estrecha su vinculación con el taller del impresor a medida que el género consigue ganar cuotas de mercado, notoriedad y, sobre todo, un público masivo que compra los poemarios y lee los versos» (Poesía y edición en el Siglo de Oro, p. 18). 
En cuanto al lector, aparte de referencias sueltas en libros de apuntes o de memorias y cartas sobre lo que leía, solamente nos quedan los inventarios, normalmente post-mortem, como fuente de información de sus gustos librescos. A pesar de los reparos puestos a los inventarios hace más de treinta años por Maxime Chevalier, que nos recordaba que éstos son el reflejo de las lecturas de un viejo o persona mayor y no necesariamente sus lecturas de joven, son por lo general lo único que tenemos para calibrar los gustos de lectura ${ }^{32}$. También es verdad que los libros inventariados no representan necesariamente todas las lecturas de un individuo durante su vida, ya que podía haber leído libros prestados por un amigo o haber tenido libros que a la hora de la muerte ya no tiene, ni su presencia en un inventario indica que los hubiera leído todos. Todos nosotros tenemos libros en nuestras estanterías que seguramente no hemos leído o solamente hojeado. Pero aún así nos proporcionan una información preciosa sobre los libros que se leían y que circulaban en distintos momentos, y, si viene la tasación, su precio o valor ${ }^{33}$.

He examinado decenas de inventarios de libros para el período 1640 a 1730 para ver los libros de poesía que tenían, y los resultados son no sólo interesantes sino, creo, a veces sorprendentes. La mayoría, por supuesto, normalmente tienen pocos libros de poesía o ninguno (el caso de muchos), pero cuando se encuentra a un amante de la poesía, la búsqueda ha merecido la pena. En esta época, 1640-1730, seis inventarios destacan por la cantidad y variedad de libros de poesía que tenían: Juan de Aguilar y Acuńa, caballero de Santiago (1644), con 46 títulos distintos; el Conde de Villaumbrosa y Marqués de Montealegre (1677), con 50; Vincencio Juan de Lastanosa (1684), con 27; Antonio Solís, escritor (1686), con 64; Domingo de Urbizo, caballero de Calatrava (1701), con 30; y Martín Antonio de Vega y Mauleón (1703), con 23. Otros, sin llegar a estos números, tampoco defraudan: Antonio Méndez Freyre, Capellán de la Emperatriz María de Austria (1652), tenía 11 títulos; Juan Valero, secretario de Felipe IV (1653), 16; Doña María Bravo de Hinojosa (1666), 11; Miguel Pérez de Mendoza, maestro de armas riojano de Carlos II (1679), 7; D. Pedro Gregorio y Antillón, obispo de Huesca (1686), 15; Manuel Mayers Caramuel, contraste de oro y plata (1693), 18; Diego Sarmiento y Valladares, obispo de Plasencia e Inquisidor

32. Ver Maxime Chevalier, Lectura y lectores en la España del Siglo XVI y XVII, Madrid, Turner, 1976.

33. Sobre el valor y las limitaciones de los inventarios post-mortem, ver Trevor J. Dadson, Libros, lectores y lecturas: Estudios sobre bibliotecas particulares españolas del Siglo de Oro, Madrid, Arco/Libros, 1998, cap. 1 «Las bibliotecas particulares en el Siglo de Oro: sus fuentes, su formación y su función». 
General (1695), 7; José de Arroyo, arquitecto (1695), 11; Miguel Nava Díez de Robles, jurado de Toledo (1698), 15; Gaspar Esteban Murillo, hijo del pintor (1709), 7; Martín Marcelino de Vergara (1726), 13; José Minguel (1729), 12. En total encontré unos 60 inventarios con libros de poesía para el período $1640-1730^{34}$.

Y, ¿qué títulos tenían, cuáles eran los libros de poesía más populares entre este variado público de escritores, burócratas, nobles, obispos, profesionales y mujeres? Aquí viene lo sorprendente, ya que por el gráfico que mostré antes, deberían ser principalmente las poesías de Lope de Vega y Alonso de Ledesma, pero no lo son, al menos a lo que a este último se refiere. Los poetas más populares a juzgar por la presencia de sus libros en estos inventarios son: Lope de Vega, Francisco de Quevedo, y Luis de Góngora, con mucha diferencia, seguidos por el conde de Villamediana, los hermanos Argensola, Fray Hortensio Félix Paravicino, Juan de Mena, Alonso de Ercilla y Zúńiga, el príncipe de Esquilache, Luis de Ulloa y Pereira, Francisco López de Zárate, Gabriel Bocángel y Unzueta, y Sor Juana Inés de la Cruz. Si un lector tenía las obras de Góngora, infaliblemente tenía las de Quevedo también; es muy raro encontrar a uno y no al otro. Divididos en la vida pero juntos en la muerte, parece ser el mensaje de estos inventarios:

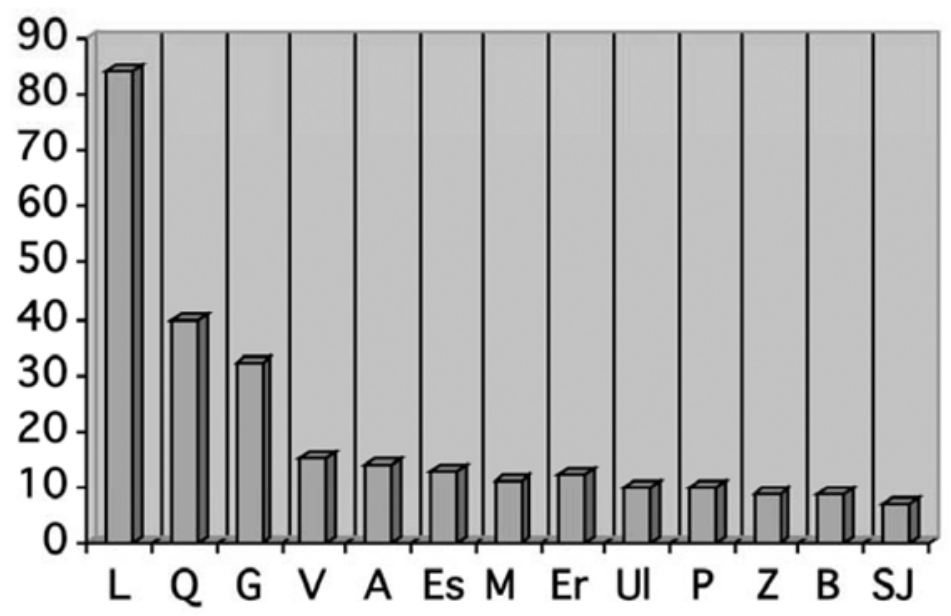

Número de ejemplares que se encuentran en bibliotecas particulares entre 1640 y $1730^{35}$

34. Éstos son en su gran mayoría inventarios hechos en Madrid, aunque 11 de ellos proceden de Salamanca (ver Ángel Weruaga Prieto, Libros y lectura en Salamanca. Del Barroco a la Ilustración 1650-1725, Salamanca, Junta de Castilla y León, 1993).

35. Leyenda: $\mathrm{L}=$ Lope, $\mathrm{Q}=$ Quevedo, $\mathrm{G}=$ Góngora, $\mathrm{V}=$ Villamediana, $\mathrm{A}=$ los Argensola, 
Lope destaca por encima de todos los demás, simplemente porque, como vimos antes, se imprimieron muchas más ediciones de sus obras que de las de sus competidores, y éstas empezaron a circular a partir de finales del siglo XVI, mientras que las obras de Góngora no empiezan a imprimirse hasta finales de la década de 1620, y las de Quevedo no aparecen hasta 1648. Las Rimas de Lupercio y Bartolomé Leonardo de Argensola no se imprimen hasta 1634 , las Obras de Villamediana se imprimen por primera vez en 1629, las de Paravicino en 1641, las de Esquilache en 1648, y las de Bocángel en 1627 y 1637. Las Obras de Luis de Ulloa y Pereira se imprimen en Madrid en 1659, el popular Poema heroico a la invención de la Cruz de Francisco López de Zárate en Madrid en 1648, y las Obras de Sor Juana Inés de la Cruz no empiezan a conocerse, impresas, hasta 1689. Es decir, Lope llevaba una ventaja de tiempo muy clara sobre los demás poetas de su época. Otra manera de ver el panorama es contar el número de inventarios en que aparecen obras de estos poetas, es decir constatar la presencia del poeta, sin contar el número de libros suyos en cada inventario. El siguiente gráfico es muy interesante en este sentido, ya que ahora las diferencias entre los tres poetas más importantes del siglo XVII se hacen más tenues y aparece otra visión de su popularidad:

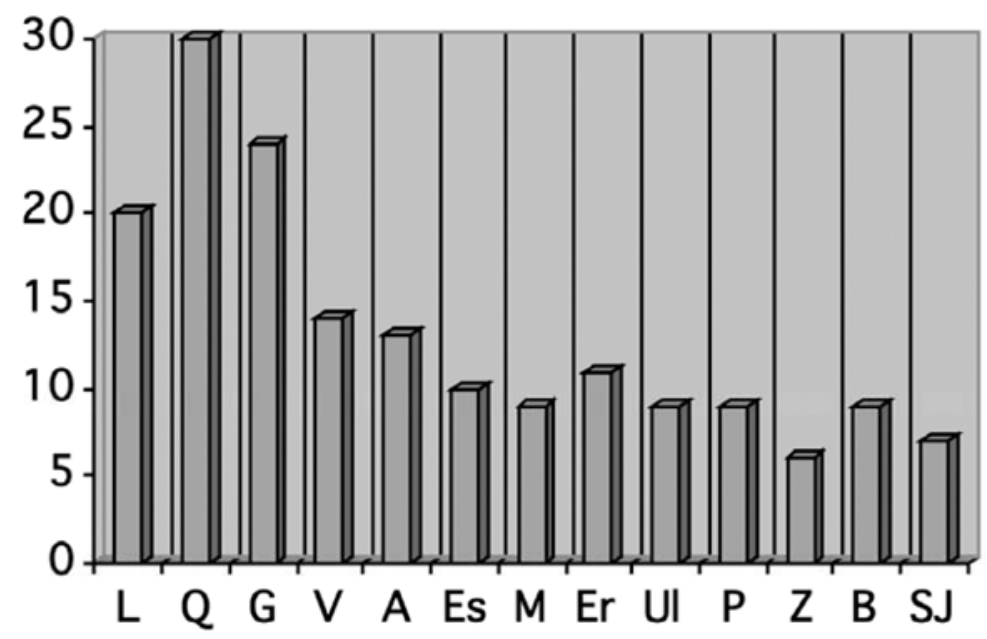

Número de bibliotecas en que figuran los poetas más populares, $1640-1730$

Es = Esquilache, $\mathrm{M}=$ Mena, Er = Ercilla, Ul = Ulloa y Pereira, $\mathrm{P}=$ Paravicino, $\mathrm{Z}=$ López de Zárate, $\mathrm{B}=$ Bocángel y Unzueta, $\mathrm{SJ}=$ Sor Juana Inés de la Cruz. 
También es curioso ver la duradera popularidad de las Trescientas de Juan de Mena y la Araucana de Alonso de Ercilla y Zúniga, que aún aparecen en inventarios del siglo XVIII. Salta a la vista que, a pesar de su enorme popularidad durante los primeros veinte años del siglo XVII, los Conceptos espirituales de Alonso de Ledesma rápidamente pasaron de moda y su presencia en bibliotecas particulares de la segunda mitad del XVII es mínima.

Una faceta de los inventarios post-mortem que nunca deja de sorprender al lector de ellos es la falta de títulos que uno esperaría encontrar. A modo de ejemplo, no sería descabellado imaginar que, al igual que un pintor o arquitecto suele tener libros profesionales en sus estantes o cajones, un escritor también tendría libros de literatura, diversión o entretenimiento, textos de sus autores favoritos, de los que más hubieran influido en su obra. Éste sí es el caso con el poeta, cortesano y político Diego de Silva y Mendoza, conde de Salinas y marqués de Alenquer (1564-1630), en cuya biblioteca encontramos la poesía de Ausías March, Jorge Manrique, Juan de Mena, Camóes, Francisco de Figueroa, Garcilaso, y la Primera parte de las Flores de poetas ilustres de España de Pedro de Espinosa, que recoge dos poemas del conde $^{36}$. Ninguno de estos poetas sorprende, representan el paisaje mental y poético de Salinas. Pero si tomamos el ejemplo del conde de Rebolledo, cuyas obras poéticas, tituladas Ocios, fueron impresas en Amberes en 1660, de poesía solamente encontramos el Poema heroico de la invención de la Cruz de Francisco López de Zárate (Madrid, 1648) ${ }^{37}$. Sin embargo, en unos tercetos que escribió a un amigo, «que, a persuasión suya, se había retirado de un galanteo y deseaba darse al estudio", nombró a sus poetas favoritos españoles:

Cuando el largo camino les asombre, descansen, como en sitios singulares, en los poetas de famoso nombre.

[...]

En acordar los españoles tardo,

Osías March, Garcilaso, Juan de Mena,

Camóes, la Torre, este y aquel Leonardo,

36. Para la biblioteca de Salinas, ver Trevor J. Dadson, Libros, lectores y lecturas, op. cit., p. 205-214 y 391-409.

37. Ver María Concepción Casado Lobato, «La biblioteca de un escritor del siglo XVII: Bernardino de Rebolledo», Revista de Filología Española, no 56, 1973, p. 229-328. 
Góngora, y otros, de qu'está tan llena

España ya, que con heroica trompa

en sonoroso aliento el aire atruena ${ }^{38}$.

Pero no tenía, al parecer, ninguno de ellos en su biblioteca. Otro que mostró poca afición por los de su gremio era Rodrigo Caro (1647). En una biblioteca de unos 530 títulos, sólo tenía las siguientes obras de poesía: «Soledades de Don Luis de Góngora. 4 rs [la edición comentada por García Coronel. Madrid, 1636]; Versos de Herrera, de a quartillo, Sevilla 1619. 4 rs; Las obras de Juan de Mena. Salamanca 1552, de a 16.4 rs» ${ }^{39}$. Incluso en los inventarios que sí tienen libros de poesía, puede haber sorpresas. Extraña no encontrar ningún ejemplar de las Rimas de los hermanos Argensola en la biblioteca de Vincencio Juan de Lastanosa, el gran bibliófilo oscense. ¿Vamos, por eso, a creer que no las tenía, que no las había leído? ${ }^{40}$

Otro aspecto que quiero señalar de este escrutinio de los inventarios de libros es cómo algunos textos se encuentran aún muchos años después de su publicación, en particular libros que solamente se imprimieron una vez, como la Primera parte de las Flores de poetas ilustres de Pedro de Espinosa (impreso en Valladolid en 1605), presente en la biblioteca del pintor Diego de Silva y Velázquez en 1660, en la del secretario real Francisco Gracián Berruguete de 1678, y en la de Lastanosa en 1684, casi 80 años después de su impresión; o las Obras de Luis Carrillo y Sotomayor (impresas en Madrid en 1611 y 1613) y presente en la biblioteca de la dama trujillana Ana María de Bauls, en 1716, más de un siglo después; o las Rimas de Juan de Jáuregui (impresas en Sevilla en 1618), libro que aparece en la gran biblioteca de Antonio de Solís en 1686; o las Obras de Diego Hurtado de Mendoza, cuya única edición conocida es de 1610, presente en la biblioteca de D. Miguel Nava Díez de Robles, jurado de Toledo, en 1698, y en el de D. Domingo de Urbizo en 1701, unos 90 años después de su publicación; o, del mismo lector, las Rimas de los hermanos Argensola, impresas en 1634, más de 65 años antes; o el caso muy parecido del popular Rimas humanas y divinas del Licenciado Tomé de Burguillos de Lope, impreso también en 1634 y presente en 1698 en la biblioteca de don Antonio Gil Fornell, ayuda de cámara de

38. Ocios, Amberes, Plantiniana, 1660, p. 159-160. Ver también Rafael González Cañal, Edición critica de los Ocios del conde de Rebolledo, Cuenca, Ediciones de la Universidad de Castilla-La Mancha, 1997, p. 348-349.

39. Jean-Pierre Etienvre, "Libros y lecturas de Rodrigo Caro", Cuadernos bibliográficos, $\mathrm{n}^{\circ} 38,1979$, p. 31-106.

40. Lo que sí tenía era un ejemplar de la edición Vicuña de 1627 de las obras de Góngora, libro retirado por orden de la Inquisición poco después de su aparición en el mercado. 
Juan José de Austria, y en 1703 en la de don Martín Antonio de Vega y Mauleón ${ }^{41}$. Esta pervivencia o durabilidad de ciertos títulos y autores es aún más notable cuando entramos bien en el siglo XVIII. La biblioteca del hidalgo castellonense D. José Minguel, inventariada en 1729, contenía los siguientes libros de poesía:

Laurel de Apolo de Lope, 6 rs

Dos tomos Agudezas de Juan Owen, 12 rs

Fama póstuma de Lope, 5 rs

La Circe de Lope falto de tres hojas, 5 rs

Obras de Villamediana manchado, 5 rs

Tres tomos poesías de Sor Juana, 15 rs

Cinco tomos obras de Quevedo, los dos impresión de Barcelona y los

tres de Musas y políticas en Madrid, 30 rs

Un tomo Obras de Góngora, 6 rs

Un tomo Obras de Arteaga, 3 rs

Avisos para la muerte, 2 rs

Las Auroras de Diana, 5 rs

El Laurel de Apolo de Lope fue impreso una vez sólo, en Madrid en 1630; la Fama póstuma a la vida y muerte del doctor frey Lope Félix de Vega Carpio, editado por Juan Pérez de Montalbán y costeado por el padre de éste, Alonso Pérez, fue impreso en la Imprenta del Reino en 1636; La Circe con otras rimas y prosas de Lope fue impresa por la Viuda de Alonso Martín en 1624; las Obras de Villamediana se publicaron, al parecer por última vez en el siglo XVII, en Barcelona en 1648; las Obras posthumas, divinas y humanas de Fray Hortensio Félix Paravicino de Arteaga se imprimieron en 1641, 1645 y 1650. En algunos casos, entonces, estamos hablando de un intervalo de más de cien ańos entre la impresión de tal libro y su presencia en una biblioteca particular, y en otros de más de setenta ${ }^{42}$.

41. Para los inventarios mencionados de aquí en adelante, ver la lista de inventarios citados al final de este trabajo.

42. Vemos lo mismo con la excelente colección de libros de poesía que formaban parte de los bienes dotales entregados por el caballero navarro don Martín Antonio de Vega y Mauleón a su mujer dońa Isabel de Andicano en 1703: La Arcadia de Lope, 5 rs; Agudezas de Juan Owen primera y segunda parte, 16 rs [Madrid, 1674]; Comedias y poesías de Solís, 40 rs [Madrid, 1692]; Corona trágica de Lope, 8 rs [Madrid, 1627]; El Macabeo de Miguel Silveira, 40 rs [Nápoles, 1638]; Fama postúma de Lope, 6 rs [Madrid, 1636]; Justa poética de Lope, 8 rs [Madrid, 1620]; El Laurel de Apolo de Lope, 8 rs [Madrid, 1630]; La Circe de Lope, 12 rs [Madrid, 1624]; La Vega del Parnaso de Lope, 8 rs [Madrid, 1637]; Obras de Esquilache, 140 rs [Madrid, 1650]; Obras de Góngora de Flandes, 36 rs [Bruselas, 1659]; Obras de Ulloa, 15 rs [Madrid, 1659]; Obras de Sor Juana Inés, 26 rs [Zaragoza, 1682]; 
Parte de esta sorprendente presencia tantos años después de la publicación inicial ha de deberse al movimiento o circulación de textos mediante las subastas o almonedas, que eran un aspecto muy habitual de la vida libresca de todas las grandes ciudades españolas del siglo XVII. Las almonedas públicas permitían a los bibliófilos hacerse con libros ya muy agotados o al mero aficionado comprar por un precio razonable el libro largo tiempo buscado. La información proporcionada por las tasaciones junto con los inventarios nos permite hacernos una idea del movimiento de precios en cuanto a ciertos libros. Naturalmente, esto sólo es posible cuando no hay duda acerca del libro y edición en cuestión. Como buen ejemplo, podíamos considerar el precio de las Rimas de los hermanos Argensola, impresas en 1634 en Zaragoza $^{43}$. El precio de venta del libro era, según la Tasa, 266 maravedís, o unos 7,8 reales. Lo más probable es que se vendiera a 8 reales. Menos de 20 años después, uno podía comprar un ejemplar por 4 reales asistiendo a la subasta de los libros del secretario real Juan Valera (1653) o visitando en la misma década la librería de Blas López Calderón en Valladolid. En 1679, el ejemplar que pertenecía al maestro de armas riojano Miguel Pérez de Mendoza se valoraba en 6 reales, todavía por debajo de su precio original. Éste se alcanza en 1686 (Antonio de Solís y D. Pedro Gregorio y Antillón, obispo de Huesca) y en 1693 (Manuel Mayers Caramuel), para luego bajar a 7 reales en 1698 (Miguel Nava Díez de Robles), el mismo precio que en 1726 (Cosme Francisco Palacios). Lo que demuestra este muestrario, creo, es que el precio del libro de segunda mano anda por debajo de su precio de venta durante los primeros años de su circulación, cuando se supone que hay bastantes ejemplares a la venta y circulando, pero que empieza a subir al tiempo que escasean los ejemplares disponibles ${ }^{44}$.

Otros ejemplos son las Obras de Diego Hurtado de Mendoza, las Rimas de Tomé de Burguillos de Lope, las Obras de Esquilache, las de Paravicino y las de Villamediana. En cuanto a estos últimos, aunque hay diversas ediciones, es dudoso que difieran mucho unas de otras en lo que a su precio de venta se refiere. Las Obras de Mendoza fueron impresas una vez, en Madrid en

Obras de Villamediana, 12 rs; Obras de Mendoza, 14 rs [Madrid, 1610]; Obras de Salazar, 18 rs; Obras de Jacinto Polo, 10 rs [Zaragoza, 1670]; Obras poéticas de Cáncer, 9 rs [Madrid, 1651]; Poesías de Barrios de Flandes, 45 rs [Amberes 1674]; Poema heroico del príncipe de Esquilache, 20 rs [Zaragoza, 1651]; Rimas humanas y divinas de Lope, 10 rs [Madrid, 1634]; Triunfos divinos de Lope, 6 rs [Madrid, 1626].

43. Sobre la impresión de este libro, ver Trevor J. Dadson, Historia de la impresión de las Rimas de Lupercio y Bartolomé Leonardo de Argensola, Zaragoza, Institución «Fernando el Católico", 2010.

44. Hay que recorder que Alonso Pérez aún tenía 340 ejemplares sin vender en 1648. 
1610 por Juan de la Cuesta, y tasadas en 5 reales. Cuando murió en 1623 Francisco de Robles, el librero que había costeado la edición, aún le quedaban 914 ejemplares sin vender. En este momento fueron tasados a dos reales el ejemplar, lo que significaba una pérdida significativa sobre el precio original. En 1686 se podía comprar un ejemplar por 10 reales, en 1693 por 6, en 1698 por 10, y en 1703 por 14. Las Rimas de Burguillos (como se suele denominar el libro en los inventarios), tasadas en 6 reales el ejemplar, tiene los siguientes precios según avanza el siglo: 6 reales en 1686, 22 en 1690, 4 en 1695, 8 en 1700, 10 en 1703, y 4 en 1726. Las Obras de Esquilache, publicadas en Madrid en 1648, muestran las siguientes variaciones de precios: 4 reales en 1653, 16 en 1680, 20 y 44 en 1686, 33 en 1698, y un sorprendente 140 reales en 1703 . El valor puesto a las Obras póstumas, divinas, y humanas de Paravicino es así: 5 reales en 1669, 3 y 4 en 1686, 2 en 1696, 4 en 1698, y 3 en 1729. Las Obras de Villamediana también muestran unos precios de venta bastante similares: 6 reales en 1679, 8 en 1686 y 1693, 4 en 1695, 8 en 1698, 12 en 1703, 7 en 1716, y 5 en 1729.

El siguiente cuadro muestra cómo suben y bajan estos precios al avanzar el siglo ${ }^{45}$ :

\begin{tabular}{|l|c|c|c|c|c|c|}
\hline & Argensola & DHMendoza & Burguillos & Esquilache & Paravicino & Villamediana \\
\hline Tasa & 8 & 5 & 6 & & & \\
\hline 1653 & 4 & & & 4 & & \\
\hline 1679 & 6 & & & & 5 & 6 \\
\hline 1680 & & & & 16 & & \\
\hline 1686 & 8 & 10 & 6 & 20 & 4 & 8 \\
\hline 1690 & & & 22 & & & \\
\hline 1693 & 8 & 6 & & & & 8 \\
\hline 1695 & & & 4 & & 2 & 4 \\
\hline 1698 & 7 & 10 & & 33 & 4 & 8 \\
\hline 1700 & & & & 8 & & \\
\hline 1703 & & 14 & 10 & & & 12 \\
\hline 1716 & & & & & & 7 \\
\hline
\end{tabular}

45. No se ha incluído el precio de 140 reales pedido por las Obras de Esquilache en 1703, ya que distorsiona el gráfico, haciendo ilegible e insignificante el resto de los precios. 
Algunas ediciones gozaban de más aprecio que otras y se tasaban, por tanto, más alto. A modo de ejemplo, la edición de las Obras de Luis de Góngora impresa en Bruselas en 1659 se valoraba en 36 reales en 1703 (Martín Antonio de Vega y Mauleón) y 24 reales en 1726 (Martín Marcelino de Vergara). En ambos inventarios se especifica que es la edición «de Flandes» ${ }^{46}$. Los diversos tomos que formaban las Obras de Quevedo, impresas en Madrid en 1650 y luego en Bruselas en 1660-1661, solían valer entre 6 y 10 reales el tomo, como vemos por el inventario de José Minguel (1729): «Cinco tomos obras de Quevedo, los dos impresión de Barcelona y los tres de Musas y políticas en Madrid, 30 reales». Sin embargo, alcanzaron en 1709 el precio muy subido de 30 reales el tomo en el inventario de Pedro de Lastres y Aguilar, capellán mayor del Real Convento de la Encarnación de Madrid: "Don francisco de Quebedo obras y poesias bruselas impresos en tres thomos el ańo de mill seiscientos y cinquenta, 90 rs». No muy lejos andaban los 100 reales pedidos en 1686 por los cuatro tomos de la edición de Bruselas 1650 en el inventario de D. Pedro Gregorio y Antillón, obispo de Huesca.

Evidentemente, las diferencias de precios se pueden deber a múltiples factores: estado del mercado de libros de segunda mano en aquel momento; estado del libro a la venta -por ejemplo, el ejemplar de las Obras de Villamediana tasado en 1729 se describe como «manchado»; en el mismo inventario La Circe de Lope está "falto de tres hojas»- ; estado y calidad de la encuadernación, incluso si la lleva; y, finalmente, calidad del librero que los tasa. En algunos inventarios uno ve inmediatamente que los precios en su conjunto son altos y poco realistas, en otros parecen bajos. Los precios de los libros de poesía del inventario de José de Arroyo (1695) oscilan entre los 2 y 6 reales, mientras que los del inventario de Miguel Nava Díez de Robles (1698) van desde los 4 hasta 46. Claro que no estamos comparando en todos los casos los mismos tomos, pero cuando sí que son los mismos, los precios de este último suelen ser el doble o más del primero: obras de Villamediana -4 y 8 reales; obras de Góngora- 2 y 8 reales; Poema heroico de la invención de la Cruz de Francisco López de Zárate- 5 y 8 reales. El librero no siempre hacía bien su trabajo, y si iba con prisas, como en el caso de Damián Ruiz que tasó la librería del Almirante de Aragón, don Francisco de Mendoza, en 1625, el resultado podía ser un desastre. Ruiz tasó la gran biblioteca del Almirante en solamente un día, el 31 de enero de 1625, una biblioteca con 572 entradas (que representaban unos 814 tomos). Una semana después,

46. A la misma edición se refiere el inventario de Domingo de Urbizo (1701): «Góngora 'Sus obras' de fuera del reino". 
el 9 de febrero de 1625, se pusieron los bienes a la venta, pero como dijo algo lacónicamente el escribano que tomó nota de todo: «Doy fe que en este dicho día, aunque han acudido algunas personas a la dicha almoneda, no se ha vendido cosa ninguna». Tomás de los Arcos, encargado de la venta de los bienes del Almirante, no tardó en identificar la razón de este fracaso: «la tasa de ellos fue muy alta y subida, más de su valor, para que las personas que los viniesen a comprar llegasen a dar su valor, y ahora se está haciendo la dicha almoneda y no hay quien quiera comprarlos por estar fuera de precio y valor ${ }^{47}$. Tomás de los Arcos pidió permiso el 11 de febrero para que los mismos tasadores volvieran a tasar todo "y hagan segunda tasa en lo que meramente se valieren». Damián Ruiz hizo su segunda tasación el 25 de febrero, y esta vez no lo hizo en un día solo sino en cuatro, del 25 al 28 de febrero inclusive, señal inequívoca de que la primera tasación se había hecho con demasiada rapidez, quizá con miras a amortizar en el menos tiempo posible el salario pagado por hacerla ${ }^{48}$.

Un último detalle que quiero sustraer de este estudio de unos cuantos inventarios de libros de la segunda mitad del XVII y que será, creo, del agrado del gran gongorista Antonio Carreira, es que sólo se encuentran dos manuscritos de poesía listados y los dos son las obras manuscritas de Góngora: uno aparece en el inventario de Martín Martínez de Medrano, funcionario, en 1660, valorado en 2 reales, el otro en el inventario de D. José de Avellaneda y Sandoval, I marqués de Torremayor, en 1694, valorado en 4 reales. Son los únicos manuscritos poéticos encontrados en más de cien inventarios consultados, lo que parece desmentir la idea tan extendida de que la transmisión de la poesía en esta época se hacía mediante la copia manuscrita. Para la segunda mitad del siglo XVII el libro impreso estaba firmemente asentado como vehículo principal de transmisión de la poesía.

47. Archivo Histórico de Protocolos, Madrid: Francisco Testa, protocolo 2676, año de 1625, tomo III, fol. 1366r.

48. Para los detalles de este inventario y su venta, ver Trevor J. Dadson, «Las bibliotecas de la nobleza: dos inventarios y un librero, año de 1625», en Aurora Egido y José Enrique Laplana (eds.), Mecenazgo y Humanidades en tiempos de Lastanosa. Homenaje a Domingo Ynduráin, Zaragoza, Institución «Fernando el Católico», 2008, p. 253-302. 


\section{Inventarios Citados}

1644 «La biblioteca de Juan de Aguilar y Acuña, caballero de Santiago» (Archivo Histórico de Protocolos, Madrid: Manuel Calvo, protocolo 5525).

1647 «Libros y lecturas de Rodrigo Caro» (Jean-Pierre Etienvre, Cuadernos bibliográficos, n³8, 1979, p. 31-106).

1652 «La librería de don Antonio Méndez Freyre, capellán de la Emperatriz María de Austria» (José Luis Barrio Moya, Cuadernos de Bibliofilia (Valencia), $\mathrm{n}^{\circ} 11,1983$, p. 19-23).

1653 «La librería de don Juan Valero, secretario del rey Felipe IV» (José Luis Barrio Moya, Cuadernos de Bibliofilia (Valencia), nº 10, 1983, p. 17-31).

1658 «La librería de Blas López Calderón» (Anastasio Rojo Vega, Impresores, libreros y papeleros en Medina del Campo y Valladolid en el siglo XVII, Salamanca, Junta de Castilla y León, 1994, p. 211-233).

1660 «La biblioteca de Velázquez» (Pedro Ruiz Pérez, De la pintura y las letras. La biblioteca de Velázquez, Sevilla, Consejería de Cultura, 1999).

1660 «La librería de Velázquez» (Francisco Javier Sánchez Cantón, en Homenaje ofrecido a Menéndez Pidal, Madrid, 1925, III, p. 379-406).

1660 «La librería y otros bienes de don Martín Martínez de Medrano, funcionario del rey Felipe IV (1660)» (José Luis Barrio Moya, Cuadernospara Investigación de la Literatura Hispánica, n 15, 1992, p. 157-167).

1666 «Los libros de dońa María Bravo de Hinojosa» (Marqués del Saltillo, "Efemérides artísticas madrileñas del siglo XVII», Boletín de la Real Academia de la Historia, $\mathrm{n}^{\circ} 120,1947$, p. 633-636).

1676 «La biblioteca de un escritor del siglo XVII: Bernardino de Rebolledo» (María Concepción Casado Lobato, Revista de Filología Española, n 56, 1973 , p. 229-328).

1677 «La biblioteca poética del conde de Villaumbrosa» (Joaquín Forradellas, Boletín de la Biblioteca Menéndez Pelayo, $\mathrm{n}^{\circ}$ 48, 1972, p. 359-405).

1678 «La biblioteca del erudito madrileńo don Francisco Gracián Berruguete, "secretario de la ynterpretation de lenguas" de Felipe IV y Carlos II (1678)» (José Luis Barrio Moya, Anales del Instituto de Estudios Madrileño, $\mathrm{n}^{\circ} 46$, 2006, p. 693-706).

1679 «La biblioteca de Don Miguel Pérez de Mendoza, Maestro de Armas riojano del Rey Carlos II» (José Luis Barrio Moya, Militaria. Revista de Cultura Militar, ${ }^{\circ} 15,2001$, p. 119-137).

1684 "The Library of Vincencio Juan de Lastanosa» (Karl-Ludwig Selig, The Library of Vincencio Juan de Lastanosa, Patron of Gracián, Genève, Librairie E. Droz, 1960).

1686 «La biblioteca de Antonio de Solís» (Frédéric Serralta, Cahiers du Monde Hispanique et Luso-brésilien (Caravelle), n 33, 1979, p. 103-132).

1686 «Los libros y las obras de arte de don Pedro Gregorio y Antillón, obispo de Huesca de 1686 a 1707» (José Luis Barrio Moya, Argensola, nº 89, 1980, p. 5-53). 
1693 «La librería de Manuel Mayers Caramuel, contraste de oro y plata de Felipe IV y Carlos II (1693)» (José Luis Barrio Moya, Cuadernos para Investigación de la Literatura Hispánica, n 21, 1996, p. 181-210).

1694 «La librería de don José de Avellaneda y Sandoval, primer marqués de Torremayor (1694)» (José Luis Barrio Moya, Cuadernos para Investigación de la Literatura Hispánica, n 25, 2000, p. 281-295).

1695 «El inventario de los bienes de Don Diego Sarmiento y Valladares, obispo de Plasencia e Inquisidor General durante el reinado de Carlos II (1695)» (José Luis Barrio Moya, Museo de Pontevedra, 1994, p. 437-510).

1695 «Los libros del arquitecto José de Arroyo» (José Luis Barrio Moya, Revista de Archivos, Bibliotecas y Museos, $\mathrm{n}^{\circ}$ 81, 1978, p. 825-834).

1698 «La biblioteca de Don Miguel Nava Díez de Robles, jurado de la ciudad de Toledo (1698)» (José Luis Barrio Moya, Anales Toledanos, n 35, 1998, p. 167-178).

1698 «La librería de don Antonio Gil Fornell, ayuda de cámara de don Juan José de Austria (1698)» (José Luis Barrio Moya, Cuadernos para Investigación de la Literatura Hispánica, n 22, 1997, p. 91-103).

1701 "La librería de don Domingo de Urbizu, caballero de la Orden de Calatrava» (María Jesús Sanz y María Teresa Dabrio, «Bibliotecas sevillanas del período barroco, datos para su estudio", Archivo Hispalense, n 60-184, 1977, p. 122-155).

1703 «La carta de dote del caballero navarro don Martín Antonio de Vega y Mauleón (1703)» (José Luis Barrio Moya, Boletín de la Real Sociedad Bascongada de los Amigos del País, n 63, 2007, p. 145-166).

1709 «La biblioteca de Murillo» (Santiago Montoto, Bibliografía Hispánica, n 7 , julio 1946, p. 464-479).

1709 «La librería de Don Pedro de Lastres y Aguilar, capellán mayor del Real Convento de la Encarnación de Madrid (1709)» (José Luis Barrio Moya, La Ciudad de Dios, n² 209, 1996, p. 627-668).

1716 «La biblioteca de la dama trujillana dońa Ana María de Bauls (1716)» (José Luis Barrio Moya, XXVI Coloquios Históricos de Extremadura, 1997, p. 3544).

1726 «La biblioteca del clérigo oscense don Cosme Francisco Palacios, capellán de Felipe V en la real capilla de San Isidro de Madrid (1726)» (José Luis Barrio Moya, Argensola, n 112, 1998-2002, p. 213-224).

1726 «La biblioteca de don Martín Marcelino de Vergara, escribano mayor del ayuntamiento de Madrid durante el reinado de Felipe V (1726)» (José Luis Barrio Moya, Cuadernos para Investigación de la Literatura Hispánica, n 30, 2005, p. 341-363).

1729 «La librería del hidalgo castellonense Don José Minguel (1729)» (José Luis Barrio Moya, Boletín de la Sociedad Castellonense de Cultura, $\mathrm{n}^{\circ}$ 73, 1997, p. 23-46). 


\section{BiBLIOGRAFÍA}

Carreira Antonio, «El manuscrito como transmisor de humanidades en la España del Barroco», en P. Aullón de Haro (ed.) Barroco, Madrid, Verbum, 2004, p. $597-$ 618.

Casado Lobato María Concepción, «La biblioteca de un escritor del siglo XVII: Bernardino de Rebolledo", Revista de Filología Española, n 56, 1973, p. 229328.

Cayuela Anne, Alonso Pérez de Montalbán. Un librero en el Madrid de los Austrias, Madrid, Calambur, 2005.

Chevalier Maxime, Lectura y lectores en la España del Siglo XVI y XVII, Madrid, Turner, 1976.

Dadson Trevor J., «Some Problems Connected with the Printing and Dating of Gabriel Bocángel's La lira de las Musas", Modern Language Review, n 76, 1982, p. 848-859.

— «El autor, la imprenta, y la corrección de pruebas en el siglo XVII», El Crotalón. Anuario de Filología Española, n ${ }^{\circ}$ 1, 1984, p. 1053-1068.

- "Hacia una edición crítica de la poesía del Conde de Salinas», en J. Cañedo \& I. Arellano (eds.), Edición y Anotación de Textos del Siglo de Oro, Pamplona, Anejos de RILCE, 4, 1987, p. 51-68.

— «La librería de Miguel Martínez (1629), librero y editor del primer tercio del siglo XVII», Bulletin Hispanique, n 99 , 1997, p. 41-71.

- «La librería de Cristóbal López (1606): Estudio y análisis de una librería madrileña de principios del siglo XVII», en Pedro Cátedra \& María Luisa Vidriero (eds.), El libro antiguo español IV. Coleccionismo y Bibliotecas (Siglos XVIXVIII), Salamanca, Universidad de Salamanca, Sociedad Española de Historia del Libro, 1998, p. 167-234.

- Libros, lectores y lecturas: Estudios sobre bibliotecas particulares españolas del Siglo de Oro, Madrid, Arco/Libros, 1998.

— «La corrección de pruebas (y un libro de poesía)», en Francisco Rico (ed.), Imprenta y crítica textual en el Siglo de Oro, Valladolid, Fundación Santander Central Hispano. Centro para la Edición de los Clásicos Españoles, 2000, p. $97-$ 128.

— "The Dissemination of Poetry in Sixteenth-Century Spain», Journal of the Institute of Romance Studies, n ${ }^{\circ} 8,2000$, p. 47-56.

- «Entre componedores y correctores», en José Manuel Lucía Megías (ed.), Imprenta, libros y lectura en la España del Quijote, Madrid, Ollero y Ramos, 2006, p. 225-242.

— «Editing the Poetry of don Diego de Silva y Mendoza, Count of Salinas and Marquis of Alenquer", Bulletin of Hispanic Studies, n 85, 2008, p. 285-331.

— «Las bibliotecas de la nobleza: dos inventarios y un librero, año de 1625», en Aurora Egido y José Enrique Laplana (eds.), Mecenazgo y Humanidades en tiempos 
de Lastanosa. Homenaje a Domingo Ynduráin, Zaragoza, Institución «Fernando el Católico", 2008, p. 253-302.

— «La imprenta manual y los textos poéticos», Edad de Oro, n 28, 2009, p. 73104.

- Historia de la impresión de las Rimas de Lupercio y Bartolomé Leonardo de Argensola, Zaragoza, Institución «Fernando el Católico», 2010.

— «El mercado del libro en Madrid durante el primer tercio del siglo XVII. Algunos apuntes y un inventario", Litterae [en prensa].

Etienvre, Jean-Pierre, «Libros y lecturas de Rodrigo Caro», Cuadernos bibliográficos, $n^{\circ} 38,1979$, p. 31-106.

García Aguilar, Ignacio, Imprenta y Literatura en el Siglo de Oro. La poesía de Lope de Vega, Madrid, Ediciones del Orto/Universidad de Minnesota, 2006.

- Poesía y edición en el Siglo de Oro, Madrid, Calambur, 2009.

Garcilaso de la Vega, Obras completas, ed. Elías L. Rivers, Madrid, Castalia, 1968.

González Cañal, Rafael, Edición crítica de los Ocios del conde de Rebolledo, Cuenca, Ediciones de la Universidad de Castilla-La Mancha, 1997.

Jauralde Pou, Pablo, «El público y la realidad histórica de la literatura española de los siglos XVI y XVII», Edad de Oro, no 1, 1982, p. 55-64.

Laspéras, Jean Michel, "El fondo de librería de Francisco de Robles, editor de Cervantes», Cuadernos Bibliográficos, no 37, 1979, p. 107-138.

León, Fray Luis de, Poesías, ed. P. Ángel Custodio Vega, Barcelona, Planeta, 1970.

Moll, Jaime, «El libro en el siglo de oro", Edad de Oro, n 1, 1982, p. 43-54.

Paredes, Alonso Víctor de, Institución y origen del Arte de la Imprenta y reglas generales para los componedores, edición y prólogo de Jaime Moll, Madrid, El Crotalón, 1984; segunda edición: Madrid, Calambur, 2002.

Péligry, Christian, «El inventario de Sebastián de Robles, librero madrileño del siglo XVII», Cuadernos Bibliográficos, n 32, 1975, p. 181-188.

— «Un libraire madrilène du siècle d'or. Francisco López le Jeune (1545-1608)», Mélanges de la Casa de Velázquez, n 12, 1976, p. 219-250.

- "Les difficultés de l'édition castillane au XVII" siècle, Mélanges de la Casa de Velázquez, $\mathrm{n}^{\circ} 13,1977$, p. 257-284.

Rodríguez-Moñino, Antonio, Construcción crítica y realidad histórica en la poesía española de los siglos XVI y XVII, Madrid, Castalia, 1968.

- Manual bibliográfico de cancioneros y romanceros impresos durante el siglo XVII, 2 vols, Madrid, Castalia, 1977-1978.

Saltillo, marqués del, "Bibliotecas, libreros e impresores madrileños del siglo XVII», Revista de Archivos, Bibliotecas y Museos, n 54, 1948, p. 255-285.

Simón Díaz, José, "Los escritores-criados en la época de los Austrias», Revista de la Universidad Complutense, $\mathrm{n}^{\circ}$ 2, 1981, p. 169-178.

- "Censo de escritores al servicio de los Austrias», en Censo de escritores al servicio de los Austrias y otros estudios bibliográficos, Madrid, C.S.I.C., 1983, p. 7-32.

Weruaga Prieto, Ángel, Libros y lectura en Salamanca. Del Barroco a la Ilustración 1650-1725, Salamanca, Junta de Castilla y León, 1993. 